\title{
Study on Refusal Strategies and Implication to English
}

\section{Teaching}

\section{Tian Xibo}

Dongfang College of Zhejiang University of Finance and Economics, China

Received: 02 Jan 2021; Received in revised form: 26 Feb 2021; Accepted: 25 Mar 2021; Available online: 18 Apr 2021 (C)2021 The Author(s). Published by The Shillonga Publication. This is an open access article under the CC BY license (https://creativecommons.org/licenses/by/4.0/).

\begin{abstract}
This study makes an analysis of the refusal strategies of 30 native speakers of English (NS) and 50 Chinese EFL learners (NNS). It implicates that the latter adopts more strategies than the former when making a refusal in general. Both groups adopts more indirect strategies than direct strategies, and the order and frequency of semantic formulas in each situation were different in different situations. So in English teaching, teachers should focus on developing the learners' ability to overcome obstacles in communicative interactions and to become strategically competent.
\end{abstract}

Keywords—refusal strategies, indirect strategies, direct strategies, English teaching.

\section{INTRODUCTION}

As we know, the speech act of refusal is a face threatening act in our daily life. According to Brown and Levinson (1978), face is "a public self-image that every member wants to claim for himself" (Brown and Levinson (1978). When we refuse others, the interlocutor's face may be threatened more or less. Besides, fewer studies are made on the speech act of refusal. In order to make up for the vacancy in pragmatics, the following thesis is concerned with the performance of the speech act of refusal, one of the most important pragmatic competences.

\section{LITERATURE REVIEW}

Several comparative studies have been conducted on refusals, which includes the refusal study conducted in 1985 by Beebe and Gumming, who compared refusals in spontaneous speech and written discourse completion tasks and the follow-up study by Takahashi and Beebe (1987), who investigated written refusals by native speakers of English, native speakers of Japanese, Japanese ESL students in the United States, and Japanese EFL students in
Japan.

Then the study by Beebe, Takahashi, and Uliss-Weltz (1990) revealed the interaction of status with directness of the refusals. Stevens (1993) studied Arabic and English refusals by using a written DCT, which is similar to those of Beebe et al. (1990) and Hussein (1995) discussed making refusals in Arabic as part of a larger study of speech acts in Arabic. Besides, Nelson et al. (2002) studied Egyptian Arabic and American Refusals using a written DCT.

After a brief review of the speech act literature, we know that there is little study in literature on the study of the refusal speech act, especially the contrastive study between native speakers of English and Chinese EFL learners. Besides, I am interested in refusal speech act made by Chinese EFL learners because the concept of refusal constitutes a challenging concept to the Chinese communicators.

This study investigated the similarities and differences of refusal strategies made by native speakers of English and Chinese EFL learners. The research questions 
in this study are:

1. Does the frequency of direct and indirect strategies used differ between Chinese EFL learners and native speakers of English?

2. Do Chinese EFL learners and native speakers of English use different strategies in terms of order and frequency of semantic formulas?

3. Does the status of interlocutor affect their refusal strategies use between Chinese EFL learners and native speakers of English?

This study is of value in three aspects:

Firstly, it enhances the chances of interactional success and promotes cross-cultural communicative competence. Secondly, it enhances the Chinese English learners' awareness of the cultural differences. Thirdly, implications based on the findings of the study provide helpful suggestions on improvement of teaching English as a foreign language, which will be of practical value to the daily classroom teaching and learning.

Apart from the universally accepted principles such as the Cooperative Principle (CP) (Mey J. L. 2005) and Politeness Principle (PP) (Mey J. L. 2005), Brown and Levinson's Face Theory is also acceptable in explaining different speech act. (1987, cited in Spenser-Oatey 2000).

\section{THE METHOD AND SUBJECTS OF THE SURVEY}

\subsection{Subjects}

Eighty subjects participated in this study: 30 native speakers of English (NS) and 50 Chinese EFL learners (NNS). The native speakers of English are between 23 and 46 years of age, who are studying in Xi'an International Studies University, all of whom have bachelor's degrees. The Chinese EFL learners are students who are now studying in Xi'an international studies University in Grade Two, all of whom are non-English major students and they are about 20 to 21 years old. To avoid the pragmatic statistic error caused by the subjects' English proficiency, the Chinese students whose CET 4 scores are more than 65 are chosen as the subjects of NNS group.

\subsection{Materials}

In this study, the Discourse Completion Test (DCT) employed by Beebe et al. (1990) (see Appendix A) was used to collect the data. All the subjects of both groups were asked to fill out the DCT in English.

\subsection{Method and Procedure of Data Collection}

All 80 subjects were asked to fill out the DCT, which was a written role-play questionnaire consisting of 12 situations randomly arranged. Each situation contained a blank in which only refusals would fit. The 12 DCT situations were categorized into four stimulus types to elicit the subject's expression of refusals: three requests, three invitations, three offers and three suggestions. In every situation, a refuser with one of the social status has set in the situation description: higher, equal, and lower (See Appendix B). The directions were written out on the DCT.

Also in this study, data were collected from the 80 subjects via responses to the 12-situation discourse questionnaires categorized by Beebe (1990) into the following refusals semantic formulas (see Figure 1which is omitted here).

\subsection{Data Analysis Methods}

As Cohen (1996) notes, one of the first concerns of speech act researchers is to arrive at a set of strategies "typically used by native speakers of the target language". A strategy is a verbal move such as a statement of regret or a reason that is used as a part of the total act of refusing. In order to arrive at a set of strategies, the utterances are divided into idea units, and then each idea unit was then coded as a specific strategy category.

In analyzing the data, I coded the order of semantic formulas used in each refusal. Besides, the frequency of each formula for each situation is calculated to investigate the difference between the two groups. Descriptive statistics were calculated in order to investigate the similarities and differences and to determine measures of central tendency and dispersion for (1) full-test refusal patterns by NS and NNS groups (including total strategies used, strategies per item, total direct strategies, total indirect strategies, and proportion of direct versus indirect); (2) the order and frequency of semantic formulas used in each situation were coded to investigate the strategies used by the two groups based on Lower, equal, or higher interlocutor status (including direct and indirect strategies used per item); (3) average frequencies of the indirect refusal strategies for each group in the full-length test, and 
on lower, equal, or higher interlocutor status items.

A Chi-square test was conducted in SPSS 10.0 in order to determine whether observed differences in average frequency of strategies employed by each group were statistically significant, and whether observed differences in frequency of strategies employed by each group in each situation were statically significant: Graphic displays were created in order to demonstrate distributions of refusal strategies used by the NS and NNS groups on the full-length test as on lower, equal, and higher status item types. Nevertheless, descriptive statistics and graphic displays enable observation of apparent patterns in the data.

\section{RESULTS ANALYSIS AND DISCUSSION}

4.1 Results analysis

Firstly, on average, both the NS group and NNS groups used substantially more indirect refusal strategies than direct refusal strategies. Besides, the NNS group used more refusal strategies than did the NS group as reflected inTable1.

Secondly, it is found that both NS and NNS groups primarily use eight indirect strategies with different frequency. The most frequent strategy used by both groups was reasons, however, NNS group used them more than did NS group. Regret strategy is a common one that is frequently used in both NNS and NS. Besides, the NNS group was more like to use the alterative strategy than the NS group. They were more likely to save the threat on the interlocutors, face by using this strategy when the interlocutors are in. Also for the strategy of off hook, NS consider more of the interlocutor's feelings than the NNS.

\subsection{Discussion}

The Chinese culture is believed to be collectively oriented and the Western individually oriented. The two societies are extremely different and therefore the relationships between social factors and strategy selections in refusal discourse are distinct. In this study, the above study has proved this point.

\subsubsection{Collectivism in the Chinese Culture}

It is generally accepted that the Chinese culture is group/collectivity oriented, so every member's verbal behavior to certain maxims in certain context because the
Chinese care much for the respect of the group and a good moral reputation.

As we know, making refusals means hurt the interlocutor's face, so it does not accord with Chinese culture character---harmony. The above studies proved that Chinese EFL learners were greatly influenced by their native culture. When they have to refuse, the EFL learners prefer to use indirect strategies and use more kinds of indirect strategies to save the interlocutors' face; Also Chinese EFL learners are more sensitive to the social hierarchy. When making refusals to a person with high status, most of them chose to express the specific excuses.

In short, collectivism in Chinese and the emphasis on social relationships can partly explain why Chinese EFL learners use less direct strategies and more indirect strategies when making a refusal, why Chinese people are more sensitive to the social status, why they like to offer specific reasons in refusing a high-status. However, it may be quite difficult for the foreigners to understand or even accept such an indirect, non-confrontational and self-restraint way

\subsubsection{Individualism in the English Culture}

In the English culture, the concept of an individual self is rooted in a philosophical tradition. In the English culture, people are encouraged at a very early age to express their own preferences, make decisions for themselves, and solve their own problems.

Consequently, individualism, as compared with the Chinese collectivism, can also well explain the character of the strategies use when making refusals. They pay more attention to their own feelings. Comparing with Chinese EFL learners, they use more direct strategies even the interlocutors in higher status. They seldom express the definite reasons. They are less sensitive to the social status than Chinese.

\section{CONCLUSION}

Findings from this study indicate there are similarities and also difference between the Chinese NNS groups and NS of English group. It shows that NNS group uses more strategies than NS group when making a refusal in general. Both NS and NNS groups use more indirect strategies than direct strategies. The order and frequency of semantic 
formulas in each situation were different for both groups in different situations.

From the study we know that EFL learners are more sensitive to social status comparing with native speakers of English. This study indicated that NS group was more likely to utilize gratitude, positive opinion, regret strategies than NNS group; excuse strategies were frequently utilized by NNSs when making a refusal to persons with equal and higher status, and it was found from the questionnaires that NNSs were more likely to use specific excuses or reasons to make them sound reasonable and express their regrets, when refusing persons with higher status. But NSs seldom used specific reasons, and they usually gave a vague one. Obviously, NNS used lower frequency of excuses strategies when refusing persons with lower status.

Individualism of the western culture and collectivism of the Chinese which embodies the cultural difference has caused the linguistic difference in the strategic use of language. Therefore, for EFL learners, a good knowledge of different cultural values, social norms and conventions, habits, points of view, thinking patterns, concepts of politeness, face and FTAs is of vital importance in one's successful cross-cultural communication. As to a teacher of English as a foreign language, he/she should focus on developing the learners' ability to overcome obstacles in communicative interactions and to become strategically competent.

\section{IMPLICATIONS AND LIMITATIONS OF THE STUDY}

\subsection{Pedagogical implications}

The study implies that EFL teachers should teach learners how to minimize native interference in language learning in order to prevent impolite, ineffective or inappropriate behaviors that may bring about misunderstanding, embarrassment or offense. To avoid the would-be misunderstanding, embarrassment or offense, and develop the learners' communicative competence, teachers of both languages may focus on the following aspects:

Firstly, reinforce the learners' awareness of the cultural differences. The diversity and distinctions of cultures demand communicators should be sensitive to cultural awareness. Language teachers must not only be aware of culture and socio-linguistic differences underlying the communicative behavior of native and non-native users of English, but also transmit such awareness to their learners.

Secondly, cultivate the learners' cross-cultural communicative competence. Since using a language appropriately requires not only the knowledge of grammar but also that of communication, as communicative competence is of great significance for foreign language learning. So in the course of teaching English as a foreign language, teachers should pay special attention to developing learners' communicative competence while teaching them grammatical rules, for the development of learners' communicative competence is the main task and ultimate goal in EFL teaching.

To improve the communicative competence, there are suggestions as follows:

(1) The evaluation of a situation is a useful technique to further reinforce the learners' awareness of the factors affecting the choice of semantic formulas.

(2) Role-play activities are particularly suitable for practicing the use of speech acts. (3) Feedback and discussion are useful activities for speech act teaching.

\subsection{Limitation}

This study investigates Chinese NNS and NS of English refusal strategies by asking interviewee to respond orally to hypothetical situations. There are some limitations in this study that will be significant for the future study.

Firstly, it is important to point out that what people believe they would say in a given situation may be different from what they would say if the situation arose in daily interaction.

Secondly, one could argue that the DCT elicits the pragmalinguistic features of languages more effectively than the sociopragmatic features, because the individual could not refuse in the situation. That is the also the DCT's limitation.

Thirdly, if we are to enhance the validity of significant differences, we must increase the number of subjects in each language group, and controls must be instituted in order to study the effects of varying 1.2 proficiency levels, 
length of years of learning English, sex of the refusers, and other factors believed to affect the data. In this study, only the status is considered.

\section{SUGGESTIONS FOR FURTHER STUDIES}

Based on the limitations of this study, some suggestions are provided for future studies.

(1) Natural speech versus questionnaire responses.

(2) Influence of contextual internal and external factors on the strategy use in refusals.

(3) Amount and tone of negotiation involved in refusal.

The DCT is lack of contextual variation, a simplification of complex interactions, and the hypothetical nature of the situations. What people claim they would say in a hypothetical situation is not necessarily what they actually would say in a real situation.

Because the speech act of refusal is complex, the future study will focus on the level of directness in refusals and on the ways in which feelings of obligation and frustration affect their form and content.

\section{REFERENCES}

[1] He Ziran, Chen Xinren. Contemporary Pragmatics[M]. Beijing: Foreign Language Teaching and Research Press. 2004.

[2] Levension, S. C. Pragmatics[M]. Foreign Language Teaching and Research Press \& Cambridge University Press. 2005.

[3] Ma Yelan. A Comparative Study of strategies between Chinese and Americans. Journal of $\mathrm{Xi}$ 'an International Studies Universities. 2001(6).

[4] Mey, J. L. Pragmatics: An Introduction (2nd ed.)[M]. Beijing: Foreign Language Teaching \& Research Press. 2005.

[5] Samovar, L. A. Communication between Cultures[M]. Beijing: Foreign Language Teaching \& Research Press. 2005. 